$(n=237)$. The imputed reductions in the risk of diabetes and cardiovascular disease were $40 \%$ and $18 \%$ respectively. All components of the metabolic syndrome apart from systolic blood pressure were improved. Intervention components included information provision, group discussions, selfmonitoring of behaviour, goal-setting, and planning for behaviour change and maintenance. Full details of the intervention and its results have been reported elsewhere. ${ }^{5}$

The success of the GGT DPP in primary healthcare settings did not go unnoticed. The Department of Human Services in Victoria has already begun implementing this programme on a large scale, with the aim of having 25000 Victorians reduce their risk of type 2 diabetes by 2011 .

\section{Nathalie Davis-Lameloise}

Research Fellow, GGT UDRH, Flinders University and Deakin University, PO Box 423 Warrnambool, Victoria 3280, Australia. E-mail: Nathalie.Davis@greaterhealth.org

\section{Benjamin Philpot}

Research Associate, Flinders University and Deakin University.

\section{Prasuna Reddy}

Professor and Director of Health Services Research, Flinders University and Deakin University.

\section{James A Dunbar}

Professor and Director of Greater Green Triangle University, Flinders University and Deakin University.

\section{REFERENCES}

1. Barclay C, Procter KL, Glendenning R, et al. Can type 2 diabetes be prevented in UK general practice? A lifestyle-change feasibility study (ISAIAH). $\mathrm{Br} \mathrm{J} \mathrm{Gen}$ Pract 2008; 58(553): 541-547.

2. Tuomilehto J, Lindstrom J, Eriksson JG, et al. Prevention of type 2 diabetes mellitus by changes in lifestyle among subjects with impaired glucose tolerance. N Engl J Med 2001; 344(18): 1343-1350.

3. Lindström J, Ilanne-Parikka P, Peltonen $\mathrm{M}$, et al. Sustained reduction in the incidence of type 2 diabetes by lifestyle intervention: follow-up of the Finnish Diabetes Prevention Study. Lancet 2006; 368(9548): 1673-1679.

4. Absetz P, Valve R, Oldenburg B, et al. Type 2 diabetes prevention in the 'real world': one-year results of the GOAL Implementation Trial. Diabetes Care 2007; 30(10): 2465-2470.

5. Laatikainen T, Dunbar JA, Chapman A, et al.
Prevention of type 2 diabetes by lifestyle intervention in an Australian primary health care setting: Greater Green Triangle (GGT) Diabetes Prevention Project. BMC Public Health 2007; 7: 249

DOI: 10.3399/bjgp08X376258

\section{APMS contracts}

I read Dr Conlon's letter in your September issue ${ }^{1}$ with some incredulity and a great feeling of sympathy for those of his employees who may have been faced with redundancy or a loss of earnings in order for the practice to avoid a financial disaster. This was, after all, an APMS contract for which he made a successful bid at a price he felt was appropriate for the services he was offering. It is absolutely vital for any practice or consortium to formulate a sound business plan in advance of any APMS contract bid to see if it is economically viable. In this case, it clearly was not. Full credit must go to the PCT, of whom I am not acknowledged to be a great admirer, for increasing the payments to $85 \%$ when there was no contractual obligation for them to do so.

I hope that this example serves as an object lesson to all those practices who may be tempted to make bids for APMS contracts without doing the most basic arithmetic. It is unfortunate that more GPs today have not had the benefit of a grounding in the Classics. If they had they would understand the meaning of the Latin expression caveat emptor.

\section{Charles Zuckerman}

Northfield Health Centre, 15 St Heliers Road, Birmingham, B31 1QT.

E-mail: charles.zuckerman@blmc.co.uk

\section{REFERENCES}

1. Conlon M, Brinksman S, Manley V, et al. The NHS at 60. Br J Gen Pract 2008; 58(554): 648.

DOI: 10.3399/bjgp08X376267

\section{Authors' response}

We wanted to trigger a debate on resource inequality in health care, so were not expecting someone to call our financial judgement into question, and use our letter to warn against APMS contracts.

First, our defence: we made careful calculations, agreed and accepted by the appointing PCT. In addition, our bid price was above the minimum recommended by the BMA at the time. In that sense, we believe that responsibility for the financial judgement is a shared matter, and directing criticism at one party unhelpful.

APMS contract setting continues to evolve, and we understand that some contracts are now approaching a fairer reflection of what is needed to provide high quality care in the local context. If this continues, then APMS may yet become an effective vehicle for redressing the inequity of resource we observed in our original letter.

That said, Dr Zuckerman makes a valid point about caveat emptor. Our experience shows the real risks that a single practice faces when bidding for an APMS contract. By comparison, large commercial organisations can probably write off the loss of an underfunded contract for several years, so as to get their foot in the door.

This, however, creates a dilemma: for existing practices to sit on their hands while commercial organisations harvest large swathes of primary care, or to seek to preserve the qualities of continuity and professionalism that characterise general practice by exposing themselves to risk. Judging the effects on health inequalities of action versus inaction is difficult. The logical alternative - for large groups of independent practices to form partnerships to increase their clout - still seems too unappealing for most GPs to follow it through.

No one held a gun to our heads, but our sense of threat to general practice was and remains strong. We chose to act by applying for this contract. Despite the financial challenge, the practice team remains positive. The majority of our patients are being treated by experienced GP principals, not locums or salaried doctors on short-term contracts. Had we been over-inhibited by caveat emptor this situation could be very different. 